\title{
Guerra y economía en Arequipa: las actividades del español Lucas de la Cotera en una coyuntura de crisis, 1821-1824
}

\author{
por \\ José Víctor Condori \\ Universidad Católica San Pablo
}

El presente artículo busca acercarse al contexto económico de una ciudad peruana durante la guerra de Independencia y a las consecuencias positivas y negativas que ella generó. Asimismo, por medio de la documentación principalmente notarial y de hacienda obtenida de archivos regionales, reconstruir las actividades politicas y empresariales del comerciante español Lucas de la Cotera, quien por diversas circunstancias, muchas de ellas favorables, se convirtió durante este breve periodo en el principal financista y abastecedor del último gobierno virreinal en el Perú.

PAlabras Clave: Independencia; Arequipa; Intendencia; patriotas; realistas; mercantil; hacienda pública; gobierno virreinal; préstamos; contribuciones; fianzas; poderes.

Don Lucas de la Cotera, un comerciante español establecido en Arequipa, a quien todos los extranjeros que llegan con carga a los puertos intermedios están obligados a encomendarse y que, debido a su riqueza, tenía gran influencia sobre el Gobernador español.

Heinrich Witt Comerciante alemán ${ }^{1}$

Cuando el 28 de julio de 1821 el general argentino José de San Martín proclamó la Independencia en la Plaza Mayor de Lima, el Perú estaba lejos de ser un país libre. Extensas zonas de su territorio aún permanecían bajo dominio

1 Witt, 1992: 35. 
español y continuarían estándolo hasta después de la decisiva batalla de Ayacucho (9 de diciembre de 1824), cuando finalmente desapareció el último virreinato de América. Fueron cuarenta los meses transcurridos entre la proclamación de San Martín y la victoria patriota en los campos de Ayacucho, durante este tiempo, ¿cómo se vivió la independencia en las diferentes regiones del sur del Perú, controladas por el ejército virreinal?, ¿de qué manera influyó el conflicto en sus respectivas economías?

Aunque tradicionalmente se ha presentado a estas regiones como «leales» al régimen virreinal, «incondicionales» proveedoras de recursos humanos y materiales para sostener el sistema a costa de la ruina de sus propias economías, es muy lamentable pero aún no contamos con las investigaciones suficientes para dar respuesta a tales interrogantes o respaldar aquellas recurrentes afirmaciones ${ }^{2}$. Lo que tenemos en realidad es una historiografía sobre la Independencia del Perú marcada desde hace muchos años por un fuerte tinte centralista, donde los sucesos acontecidos precisamente en la ciudad de Lima sirvieron como argumento para interpretar lo ocurrido en otras regiones del territorio. En tal sentido, estamos completamente seguros que sin un adecuado análisis del proceso de Independencia a partir de los contextos regionales y locales, nos encontraremos cada vez más lejos de poder explicar los diversos matices que se presentaron dentro de esta coyuntura tan compleja, en una sociedad como la peruana notoriamente marcada por contrastes y antagonismos.

En definitiva, fueron muchos de aquellos discursos especulativos y ausencias historiográficas los que nos impulsaron a realizar el presente estudio, que en realidad solo representa un pequeño esfuerzo dentro de un proyecto de mayor envergadura que hemos emprendido hace algunos años por tratar de entender esta etapa de la Independencia a partir de una óptica netamente regional y, asimismo, queremos, a través de las actividades del comerciante español Lucas de la Cotera, acercarnos a la coyuntura económica y política de una importante ciudad colonial en tiempos de guerra.

\section{AREQUIPA A FINES DE LA COLONIA}

Como consecuencia de las reformas borbónicas, se introdujo en el Perú a partir de 1784 el sistema de intendencias, por el cual el territorio fue dividido en siete circunscripciones, siendo una de ellas la Intendencia de Arequipa.

2 Quiroz Paz-Soldán, 1976: 38. 
Ubicada al sur de virreinato, comprendía los partidos de Arequipa, Camaná, Condesuyos, Cailloma, Moquegua, Arica y Tarapacá. Según el censo de 1796, habitaban esta región 135.237 personas clasificadas como españoles, mestizos, esclavos e indios. Su capital era la ciudad de Arequipa, reconocida como la «muy noble y muy leal», la «fidelísima»; sede del gobierno político, militar y eclesiástico, y residencia de la elite regional. Tenía la ciudad por ese entonces una población de 22.000 habitantes, de ellos más del 70\% se consideraban españoles ${ }^{3}$. Socialmente, dicha población se hallaba dividida en tres grupos muy notorios. Una pequeña aristocracia conformada por grandes propietarios de tierras, almaceneros y funcionarios virreinales; el vasto sector medio integrado por profesionales, comerciantes, hacendados, artesanos, empleados públicos, arrieros, chacareros, etc. Y, por debajo de todos, un heterogéneo grupo de individuos de incierto origen y dudosa reputación, residentes de los alrededores de la ciudad (pampa de Miraflores y la Ranchería) y conocidos en los documentos judiciales de la época como la «ínfima plebe» ${ }^{4}$.

Como en muchas regiones coloniales, la economía de la Intendencia descansaba principalmente sobre tres actividades: la agricultura, el comercio y la minería. Siendo una característica muy notoria de la agricultura la ausencia de grandes propiedades o haciendas en la región, desde épocas muy tempranas $^{5}$. Sin embargo, ello no fue impedimento para la formación de considerables fortunas personales y familiares, gracias a la producción de vinos y aguardientes. Tan afamadas mercancías, elaboradas en los valles de Vítor, Majes y Moquegua, constituyeron el principal producto de exportación de Arequipa hacia los mercados mineros del interior. Para principios del siglo XIX los mencionados valles producían en promedio más de 500.000 botijas, por un valor cercano al millón y medio de pesos. E1 90\% de estos vinos sirvieron para la elaboración del aguardiente de uva (hoy llamado Pisco) y comercializados a través de diversas vías a lo largo y ancho de toda la región sur y alto peruana. En el siguiente cuadro podemos apreciar los volúmenes producidos por los tres más importantes valles de Arequipa, en víspera de la Independencia.

3 Los datos sobre la visita de 1792 los encontramos en Fisher, 1981: 274-276; Gootenberg, 1995: 6-16, y Brown, 2008: 49-53 y 282-283.

4 La composición socioeconómica de Arequipa a fines del siglo XVIII la obtenemos de los importantes trabajos de Wibel, 1975; Gallagher, 1978; Buller 1988; Chambers, 2003; Brown, 2008. Para el siglo XIX, tenemos Ponce, 1980, y Betalleluz, 2004.

5 La estructura de la propiedad rural en Arequipa entre los siglos XVI y XVIl es el tema principal de los trabajos de Keith A. Davies, 1974; 1975; 1984. 
Cuadro 1. Producción de Vinos en Arequipa entre 1810-1820 (en botijas)

\begin{tabular}{|c|r|c|c|}
\hline Años & Vítor & Majes & Moquegua \\
\hline 1810 & 100.410 & 195.995 & 304.571 \\
1812 & 93.495 & 123.240 & 257.206 \\
1814 & 115.185 & 134.735 & 275.110 \\
1816 & 120.370 & 184.255 & 339.090 \\
1818 & 88.570 & 125.340 & 213.710 \\
1820 & 80.530 & 120.485 & 219.075 \\
\hline
\end{tabular}

Fuente: AAA, Diezmos de los valles de Vítor, Majes y Moquegua.

Aunque el valle de Moquegua destaca claramente por su mayor productividad (60\% del total), fue el cercano valle de Vítor el más significativo para la economía y elite local, no solo por su proximidad a la ciudad de Arequipa (63 km.), sino también porque allí se concentraban las haciendas de los más destacados vecinos y familias de la elite arequipeña como los Goyeneche, Gamio, Masías, Cossío, Rivera, Barreda, Bustamante, Oyanguren, Ureta, Moscoso, Aranibar, Alvisuri, Cuadros, O'Phelan de la Fuente, entre otros ${ }^{6}$. Antes de la Independencia, el valle de Vítor tenía una producción que oscilaba entre 80.000 y 120.000 botijas, que en forma de vinos y aguardientes se destinaban a los mercados de Arequipa, Puno y La Paz.

De manera opuesta a la viticultura, las tierras de cultivo ubicadas en los alrededores de la ciudad, conocidas hasta hoy como la «campiña» y divididas en pequeñas heredades o «chacras», se especializaron en los cultivos alimenticios o de «pan sembrar», como trigo, maíz y papa. Gracias al aprovechamiento intensivo de sus suelos y al regular abastecimiento de agua, la producción de la «campiña» pudo cubrir satisfactoriamente la demanda local e incluso generar excedentes, los cuales eran enviados a los mercados más próximos de la sierra para su comercialización. Al respecto, la Guía de Forasteros de 1796 estimó la producción agrícola anual de la Intendencia en cerca de 2 millones de pesos ${ }^{7}$, una de las más altas del periodo tardío colonial.

${ }^{6}$ La producción de vinos y estructura de propiedad en los tres valles más importantes de la región se han extraído del Archivo Arzobispal de Arequipa (AAA), Diezmos de los valles de Vítor, Majes y Moquegua: 1870-1820. La misma fuente fue utilizada por Carlos Buller en su tesis «L'économie du vin à Arequipa. Les vallées de Vítor, Majes et Moquegua entre 1770 et 1850», EHESS, Paris 2009.

7 La información sobre la «producción agrícola no especializada en vino» (Buller: 2007), conformada por el maíz, el trigo y la papa, se halla en AAA, Diezmos de Arequipa: 
La prosperidad agrícola permitió a la elite local disponer de considerables capitales para ser invertidos en especulaciones mercantiles, en consecuencia el comercio arequipeño representó durante gran parte del periodo colonial la segunda actividad en importancia. A través de él la Intendencia pudo integrarse ventajosamente con un vasto territorio que se extendía entre la región sur del virreinato (Cuzco y Puno) y los centros mineros alto peruanos (La Paz, Oruro y Potosí). Dentro de este amplio mercado, además de los tradicionales y conocidos vinos y aguardientes, Arequipa suministró gran variedad de artículos importados, los llamados «efectos de Castilla», constituidos por tejidos de todo tipo, licores finos, papel, hierro y armas. Por décadas tales efectos se obtenían de la capital del virreinato y eran abastecidos por los grandes y poderosos comerciantes agrupados en el Tribunal del Consulado de Lima; entre ellos tenemos a Juan Bautista Gárate, Matías Elizalde o Francisco Luciano Murrieta. Un ejemplo acerca de tales vínculos lo verificamos en la transacción realizada por los señores Font, Sardá y Luis Herrera y Oliva del comercio de esta ciudad, con don Francisco Luciano Murrieta del comercio de Lima, para la compra de 197 «piezas de efectos» por un valor de 50.953 pesos $^{8}$. En definitiva, por medio del comercio se lograron estrechar fuertemente los lazos económicos entre las comunidades de Lima y Arequipa, posibilitando a esta última convertirse en el principal centro de abastecimiento del gran mercado sur andino antes de la Independencia9.

Es notoria y conocida la ausencia de grandes centros mineros en la Intendencia, donde las minas existentes, salvo Cailloma ubicada en las provincias altas y Huantajaya en el lejano desierto de Tarapacá, no pasaban de ser pequeños socavones alejados de los centros poblados, con escasa demanda de fuerza de trabajo y una reducida producción, que permitía limitados márgenes de ganancia y, algunas veces, solo cubrir los gastos de mineros y operarios. Ello tal vez explique el escaso interés de la elite local por invertir grandes sumas en este rubro, en comparación a otras regiones como Cerro de Pasco o Hualgayoc. En todo caso, queda bastante claro el porqué de la condición casi marginal o secundaria de la minería dentro de la economía colonial arequipeña. Una

1780-1830. Asimismo, encontramos importante información en Cossío 1804, Barriga 1941, Tomo I: 58-59. Wibel, 1975: 63-69. Brown, 2008: 50-62.

8 Obligación de los señores Pont y Sardá y don Luis Herrera y Oliva a favor de don Francisco Luciano Murrieta, 12 de agosto de 1820, Archivo Regional de Arequipa (ARAR), Protocolos, Nazario de Rivera, legajo 818, fol. 384.

9 El comercio regional y el impacto de las reformas borbónicas son el tema principal de la tesis de Buller (1988). Hay información igualmente importante acerca de las actividades mercantiles locales en Wibel, 1975: 121-160. Chambers, 2003: 55-72. Brown, 2008: 105-166 y 215-223. 
breve descripción sobre el tema nos permitirá acercarnos un poco más a su real situación.

En las postrimerías del siglo XVIII, el número de minas en producción apenas llegaba a 54 ( $8 \%$ del total virreinal), de ellas 53 eran de plata y solo una de oro. En total realizaban esta labor cerca de 84 mineros y 649 operarios, mayormente indígenas asalariados. Según diversos registros, la producción variaba entre 65.000 y 85.000 marcos anuales, sin considerar el porcentaje que salía violando los controles estatales, es decir, por contrabando.

Dos décadas después, los problemas ya existentes se irán agudizando aún más como consecuencia del empobrecimiento de los minerales, la falta de insumos, inversiones de capital y fuerza de trabajo. En consecuencia la producción descenderá notablemente hasta situarse en promedio apenas por encima de los 30.000 marcos anuales (Cuadro 2). Dicho monto registrado en las cajas de hacienda, implicaba un valor aproximado de 250.000 pesos, es decir, el equivalente a casi la octava parte de la producción agrícola. A este respecto, es necesario hacer algunas precisiones. Primeramente, debemos de considerar que la situación crítica de la minería arequipeña no fue un fenómeno exclusivamente local, sino, más bien, el reflejo de un ciclo depresivo general por el que atravesaba la minería peruana a principios del siglo XIX, después de un esperanzador renacimiento ocurrido a finales del siglo anterior. En segundo lugar, el descenso productivo no significó de manera alguna el colapso total de la minería regional y si bien tal depresión fue mucho más notoria en los destacados yacimientos de Cailloma y Huantajaya, las labores mineras proseguirían con cierta regularidad en los llamados centros pequeños, caracterizados por la mínima demanda de inversiones y fuerza de trabajo ${ }^{10}$. Diferente será la experiencia que se vivirá años después cuando comiencen las guerras de Independencia.

\section{Cuadro 2. Producción de Plata Registrada EN LA CAJA DE AREQUIPA 1810-1820}

(en marcos)

\begin{tabular}{|l|l|}
\hline 1810 & 24.050 \\
1812 & 52.619 \\
1814 & 21.642 \\
1816 & 33.825 \\
1818 & 34.553 \\
1820 & 37.405 \\
\hline
\end{tabular}

Fuente: Fisher, 1977: 243. Deustua, 1986: 254-255.

10 Pese a la importancia económica de la Intendencia de Arequipa dentro de este periodo, 


\section{GUERRA Y ECONOMÍA EN AREQUIPA}

Los conflictos bélicos, y en general cualquier conflicto, suelen llevar a la ruina total a aquellas actividades económicas ya de por sí castigadas por una grave crisis. En el caso particular de la minería arequipeña esto es axiomático. Si hasta 1820 (Cuadro 2) la producción argentífera se había mantenido, con todas sus dificultades, por encima de los 30.000 marcos al año, con el inicio de las expediciones militares sobre la región, tanto de patriotas como de realistas, los índices de producción se derrumbarán increíblemente hasta llegar a alcanzar niveles verdaderamente insignificantes. Ese fue el caso, por ejemplo, del año 1823 , cuando la cantidad de plata registrada oficialmente en los libros de contaduría o hacienda apenas llegaba a los 413 marcos.

\section{CuAdro 3. Producción de Plata REgistrada EN LA CAJA DE AREQUIPA 1820-1825}

(en marcos)

\begin{tabular}{|r|r|}
\hline 1820 & 37.405 \\
1821 & 10.486 \\
1822 & 2.040 \\
1823 & 413 \\
1824 & 3.207 \\
1825 & 15.237 \\
\hline
\end{tabular}

Fuente: Fisher, 1977: 243. Deustua, 1986: 254-255.

¿Qué pudo haber sucedió en 1823 para que la minería haya decaído de esta forma? Fue el año en que se multiplicaron las incursiones militares sobre la Intendencia, seguidas por una estela de ocupaciones y desocupaciones de varias provincias; calamidad de la que no se libró ni la propia ciudad de Arequipa, invadida por las fuerzas colombianas del general Antonio José de Sucre en agosto de ese mismo año. De este modo, a los conocidos problemas de la minería tardío-colonial se sumaron los saqueos de los centros mineros, la confiscación de acémilas y, lo que es peor, el reclutamiento forzoso de los imprescindibles y escasos operarios a fin de engrosar con ellos las filas de ambos

no existe todavía un trabajo orgánico y sistematizado sobre la minería arequipeña en la época colonial y primeros años de la república, hasta ahora solo disponemos de breves referencias. Por lo pronto, podemos revisar Wibel, 1975: 69-73. Fisher 1977: 213-233. Malamud, 1982: 56-57. TePaske y Klein, 1982, I: 2-83. Deustua, 1986: 81-86. Brown, 2008: 83-98. Flores Guzmán, 2008: 345-369. 
ejércitos. No es de extrañar entonces, las continuas y sonoras quejas de los gremios de Cailloma y Huantajaya «por los gravísimos perjuicios que había producido la recluta en aquellos pueblos» ${ }^{11}$. Pero lo más curioso de todo fue que en medio de tales dificultades surgieron algunos proyectos de inversión minera, financiados por emprendedores vecinos de Arequipa. Lamentablemente, en su mayor parte estuvieron circunscritos a los alrededores de la ciudad y representaron solo pequeñas inversiones de capital, que en conjunto no lograron detener el brusco descenso de la producción regional ${ }^{12}$.

Problemas similares a los padecidos por la minería tuvo que afrontar la otrora exitosa y pujante industria vinatera; claro está con una notable diferencia, la guerra llegó a la región cuando esta industria atravesaba por uno de sus periodos de mayor crecimiento y prosperidad. No estamos exagerando. El promedio más alto en la producción de los valles de Vítor, Majes y Moquegua en el siglo XVIII había sido de 500.000 botijas, sin embargo, en 1816 los tres valles sobrepasaron largamente las 643.000 botijas. Si vamos un poco más lejos y comparamos estas cifras con las obtenidas el año 1821 (296.305) o 1824 (316.685), la diferencia sería abrumadora y dramática, dado que nos estamos refiriendo a la principal actividad económica de la región, fuente vital para los ingresos de la elite arequipeña durante siglos.

Cuadro 4. Producción de vinos de los Valles de Arequipa 1820-1825 (en botijas)

\begin{tabular}{|c|c|r|r|}
\hline Años & Vítor & Majes & Moquegua \\
\hline 1820 & 80.530 & 120.485 & 219.075 \\
1821 & 60.510 & 80.290 & 155.505 \\
1822 & 61.075 & 61.655 & 204.315 \\
1823 & 62.565 & 62.010 & 194.480 \\
1824 & 66.960 & 74.725 & 175.000 \\
1825 & 73.280 & 70.925 & 175.230 \\
\hline
\end{tabular}

Fuente: AAA Diezmos de los valles de Vítor, Majes y Moquegua.

11 Oficio del Ayuntamiento del partido de Tarapacá al comisionado del señor Comandante General de las tropas estacionadas en la provincia, 23 de agosto de 1822, Archivo Municipal de Arequipa (AMA), Libro de Actas del Cabildo (LAC), libro 29.

12 Entre 1820 y 1824 se constituyeron ciertas compañías de minas para la explotación de oro y plata en algunos parajes cercanos a la ciudad de Arequipa como Huasacache, Congata, Mollendo y Condoroma; la mayoría de ellas tuvieron escasa duración y mínimas inversiones de capital. ARAR, Protocolos, Manuel Primo de Luque, legajo 716, fol. 410; legajo 718, fol. 625; legajo 719, fol. 21; legajo 720, fol. 1060. 
Los registros estadísticos observados permiten comprobar sin mayores inconvenientes el brusco descenso de la producción a partir de 1821. En dicho año, el general San Martín juró la Independencia del Perú en la ciudad de Lima, mientras en esta Intendencia se iniciaban las actividades militares del general patriota Guillermo Miller, quien fue elegido precisamente por San Martín para hostilizar al ejército español y de paso hacer campaña proselitista a favor de la Independencia en los pueblos del $\operatorname{sur}^{13}$. Con mucho talento y capacidad, el oficial inglés al mando de unos 500 soldados puso en apuros durante varios meses a las fuerzas realistas muy superiores en número, provocando de paso la paralización temporal de la economía regional. Un testigo de la época nos aporta interesante información acerca del impacto que tuvieron tales incursiones militares.

Tuve la desgracia que desde esta época comenzasen a hacerse más críticas y violentas las circunstancias de la guerra de tal manera que si estas desde el curso del primer año estorbaban positivamente el expendio y extracción de frutos, llegaron en lo sucesivo a serar ( $\mathrm{sic}$ ) casi todos los recursos que necesitaba el desempeño de este negocio; recluta de gentes, requisición de mulas y caballos, dispersión de operarios y vecinos eran los efectos ordinarios y más comunes que producía la guerra y que no pueden ser ignorados por su constante notoriedad ${ }^{14}$.

«La requisición de mulas y caballos» y la «dispersión de operarios y vecinos» son señaladas por el testigo en mención como una de las consecuencias más comunes de la guerra en la región, sin embargo, sería injusto atribuir toda la responsabilidad de esta crisis exclusivamente a las actividades del ejército patriota. En numerosas ocasiones, fueron las propias fuerzas realistas quienes participaron en la destrucción de propiedades, reclutamiento de operarios y confiscación de animales de carga; unas veces para proveerse de bienes y otras, para privar al enemigo de recursos. Así sucedió en 1823, cuando, mientras se producía el avance de la segunda expedición patriota a los Puertos Intermedios, el general realista Jerónimo Valdés ordenó el «exterminio de alfalfares» que producían los valles de Lluta y Azapa ${ }^{15}$.

En el lado opuesto, las actividades comerciales experimentaron un notable crecimiento a partir de ciertas condiciones que se fueron presentando progresi-

13 El general Guillermo Miller nació en Inglaterra en 1795 y participó junto al general San Martín en la Independencia de Chile y Perú. En 1834 fue ascendido al grado de Gran Mariscal del Perú y falleció en el puerto del Callao en 1861. Es uno de los grandes personajes de la Independencia peruana y sus restos descansan en el Panteón de los Héroes de Lima.

14 Expediente seguido contra don Juan Marques por dinero que adeudaba al ramo de diezmo de Acarí y Chala, 14 de junio de 1822, AAA, Causas Civiles, legajo 66, folios 3 y 4.

15 Expediente seguido por don Ramón Folch sobre la rebaja de diezmos que remató en los años de 1823 y 1824, 18 de diciembre de 1824, AAA, Diezmos, legajo 20. 
vamente durante los años de 1821-1824. Con la caída de la Capitanía General de Santiago y, particularmente, después de la ocupación de Lima por las fuerzas patriotas del general San Martín (1821), la Intendencia de Arequipa se convirtió en nexo entre la Corona española y el último virreinato de América; y su capital, en el punto medular para el abastecimiento de toda el área andina controlada por el ejército español. Esta nueva condición de la ciudad, favorecida por las circunstancias de la guerra, llevó a una rápida mercantilización de la economía regional, gracias al acelerado desarrollo del comercio, principalmente de importación. Como efecto inmediato, los cambios se verificarán en un aumento de los ingresos fiscales, el adecuado abastecimiento de mercancías europeas y el impulso de una migración de poderosos comerciantes peninsulares, limeños y extranjeros a la región ${ }^{16}$.

Resulta bastante curioso que el arribo de una nueva oleada de grandes comerciantes e inversionistas no haya generado recelos o conflictos dentro de la comunidad mercantil arequipeña, como sí había sucedido antes con la hostil migración peninsular de mediados del siglo XVIII. Contrariamente, la recepción podría decirse que fue bastante «amistosa». La razón, ellos venían a ocupar el enorme vacío dejado por los poderosos abastecedores limeños, en circunstancias que los lazos mercantiles con la península ya tenían varios años de ruptura; además, estos nuevos hombres de negocios se encargarían de vincular económicamente a la región con mercados mucho más prósperos como Inglaterra, Francia y los Estados Unidos. En este sentido, el número de navíos que a partir de 1821 hicieron su escala en algún punto de la extensa costa arequipeña se fue multiplicando considerablemente en relación a años anteriores. En cuanto al puerto principal, no obstante que Arica, ubicado a $450 \mathrm{~km}$ al sur de la ciudad de Arequipa, contaba con inmejorables condiciones para el trafico portuario en gran escala y había sido utilizado como principal punto de acceso al Alto Perú durante la Colonia, terminó prácticamente relegado por la pequeña caleta de Quilca, debido a su cercanía a esta ciudad $(184 \mathrm{~km})$. Para muchas casas comerciales extranjeras que tenían su sede en Arequipa, la cercanía entre el puerto y la ciudad significó no solo un menor costo en el transporte, sino también la segura presencia de un fuerte contingente militar de 3.000 soldados realistas acantonados en la región.

16 Entre los principales comerciantes que arribaron a Arequipa, después de 1821, tenemos a: Lucas de la Cotera, Luis Herrera y Oliva, Juan Bautista Errea, Manuel Marcó del Pont, Francisco Luciano Murrieta, Ambrosio Ibáñez y otros. Entre los extranjeros, Tomas Crompton, Guillermo Hodgson, Santiago Ygualt, Samuel B. Mardon, Juan Moens, Guillermo Cochran, Eliphaet Smith, Andrés Mac Farlane, Roberto Page, Jorge Tood, Juan Robinson, Federico Marriot, Antón von Lotten, James Gibbson, entre los principales. 
En definitiva, el crecimiento de la actividad mercantil, muchas veces señalada, se verá claramente reflejado, por un lado, en los enormes ingresos de la aduana de Arequipa, que en el quinquenio de 1820-1824 alcanzó los 252.513 pesos en comparación a los 164.441 registrados una década atrás ${ }^{17}$. Por el otro, en la presencia cada vez más activa y dominante al interior de la sociedad local de los grandes comerciantes importadores. Uno de ellos, el más representativo y no menos influyente durante estos años fue Lucas de la Cotera.

\section{LUCAS DE LA COTERA}

El español Lucas de la Cotera fue el más importante e influyente comerciante de Arequipa entre 1821-1824, sus buenas relaciones con las autoridades españolas, incluido el propio virrey La Serna y sus enormes ingresos, lo llevaron a convertirse en el principal abastecedor y financista del gobierno virreinal en la agonía de su presencia en el Perú. Lamentablemente, por el carácter limitado de nuestro estudio solo consignaremos datos acerca de sus actividades empresariales a partir de su arribo a esta ciudad. Hecho que se produjo al parecer a mediados de 1821, luego de varios años de exitosa vida empresarial en La Paz y Potosí, dedicado a actividades comerciales y mineras. Sobre la decisión de asentar sus reales en esta región, creemos que fue motivada por dos situaciones muy particulares, aunque circunstanciales. En primer lugar, el motín de Aznapuquio (enero de 1821), que llevó a un viejo conocido suyo, el general José de la Serna, a convertirse en el nuevo virrey del Perú y establecer su nueva capital en el sur del virreinato ${ }^{18}$; y en segundo lugar, la nueva condición adquirida por la ciudad de Arequipa a partir de 1821. Cuando de manera imprevista se convirtió en nexo entre España y el virreinato peruano, así como, en el centro medular del abastecimiento comercial de todo el sur andino. A cualquier empresario con fuertes vinculaciones dentro y fuera del gobierno, y en posesión de una sólida base económica, la coyuntura se le presentaba inmejorable para la obtención de pingües ganancias.

17 Wibel, 1975: 273-274.

18 En relación a la amistad entre Cotera y La Serna, John Wibel nos afirma: «...who trough his intimacy with Viceroy Jose de la Serna, we able to obtain many special comercial concessions and often a near monopoly on Arequipa's comerce». Wibel, 1975: 277-278. Asimismo, en noviembre de 1821, Cotera afirmaba ante un notario que fue invitado por «el excelentísimo Virrey don José de la Serna, en oficio fecho en Jauja a 20 de agosto de ese año, para que hiciese un particular y extraordinario recomendable servicio en la compra de cuatro o cinco mil fusiles y quinientos sables de caballería, que sirviesen de armamento de nuestro ejército». ARAR, Protocolos, Manuel Primo de Luque, legajo 717, fol. 630. 


\section{Actividades económicas}

Tomando como base la información principalmente notarial y de hacienda hallada en los archivos arequipeños, intentamos reconstruir las actividades económicas de Lucas de la Cotera en la región, que, como ya señalamos, se iniciaron en la segunda mitad de 1821. Los documentos en mención dan testimonio de una gran variedad de inversiones e intereses llevados a cabo en un periodo bastante breve. Entre las principales sobresalen la formación de compañías mercantiles, el comercio al por mayor, los préstamos a interés, los arrendamientos de propiedades, la exportación de materias primas y la importación de los llamados efectos de Castilla y Europa. En medio de tanta diversidad, el binomio importación-exportación destaca claramente por la frecuencia de las transacciones y la magnitud de sus inversiones. Precisamente de ellas nos ocuparemos en las páginas siguientes.

En giro de las importaciones, Cotera recibía en consignación grandes volúmenes de mercancías de los numerosos barcos extranjeros que durante esos años anclaban en el pequeño puerto de Quilca. El procedimiento empleado para adquirir tales cargamentos consistía en el pago de las respectivas fianzas o derechos que las autoridades aduaneras exigían por concepto de alcabala a todas las mercancías internadas por dicho puerto ${ }^{19}$. Así lo comprobamos en aquella fianza otorgada en agosto de 1824 a favor de los señores Jeremías Sullivan, Guillermo Hodgson y Nicolás Matzon:

Por cuanto los citados van a introducir en esta real aduana varios efectos que estaban a bordo del bergantín GP Estevenson en el puerto de Quilca, con la calidad de satisfacer los correspondientes derechos de alcabala, se constituye (Cotera) en fiador de los enunciados... obligando sus bienes habidos y por haber ${ }^{20}$.

No resulta difícil comprender que muy pocos comerciantes en la ciudad estuvieron realmente en condiciones de garantizar de manera inmediata las enormes sumas de dinero exigidas en calidad de fianza por los derechos de alcabala, por cuanto ella suponía en el mejor de los casos un pago del 34\% sobre el íntegro de las mercancías, más el $6 \%$ por derecho de Consulado. Es decir, el $40 \%$ del monto principal. Parece bastante claro entonces, por qué cuando en enero de 1824 Cotera recibió en consignación el cargamento del bergantín Swallon, compuesto mayormente por tejidos finos y valorado en 38.282 pesos,

19 Fianza de don Lucas de la Cotera por don Santiago Igualt, 22 de julio de 1824, ARAR, Protocolos, Manuel Primo de Luque, legajo 721, folios 709 y 721.

20 Fianza de don Lucas de la Cotera por don Jeremías Sullivan, don Guillermo Hodgson y don Nicolás Matzon, 27 de agosto de 1824, ARAR, Protocolos, Manuel Primo de Luque, legajo 721 , fol. 764 . 
tuvo que desembolsar en la real aduana nada menos que 15.362 pesos «por este real derecho» ${ }^{21}$. Entre 1821-1824, la magnitud de sus consignaciones llegaron a ser tan elevadas, que Cotera increíblemente pudo acumular deudas con la aduana de Arequipa por cerca de 565.000 pesos en tan solo un año, cantidad que le fue finalmente abonada «a cuenta de suplementos al rey» ${ }^{22}$. Todas estas mercancías importadas o "efectos de Europa» se almacenaban en la ciudad para su posterior distribución a los mercados de Cuzco, Puno y el Alto Perú ${ }^{23}$. A este respecto, no estuvieron tan alejadas de la realidad aquellas afirmaciones del viajero alemán Heinrich Witt, quien visitó la ciudad de Arequipa a finales de 1824, cuando con relación a Cotera decía que «todos los extranjeros que llegaban con carga a los puertos intermedios, estaban obligados a encomendarse» ${ }^{24}$.

En su otra faceta como exportador, Cotera estuvo muy comprometido en el negocio de lanas, cacao y estaño con la metrópoli española. Precisamente, allí se encontraba muy bien instalado su socio Francisco Luciano Murrieta, comerciante de origen vasco y residente en la ciudad de Lima hasta mediados de 1821. Ambos personajes, en noviembre de 1822, constituyeron en Arequipa una notable compañía de negocios, con un aporte inicial de 700.000 pesos, destinada a la comercialización de «plata, frutos de América y efectos de Europa». Dentro de la mencionada compañía se consideraron de manera retroactiva «todos cuantos negocios se hallaban comprendidos desde el mes de junio de $1820 »$, fecha en que al parecer se iniciaron las relaciones económicas mancomunadas entre los susodichos, incluyendo no solo las ganancias, sino también las pérdidas que a lo largo de estos años hubiesen tenido. Tratándose de hombres de negocios tan experimentados, se entiende que no dejaran asunto alguno sin considerar, por ello para el buen funcionamiento de la empresa

21 Las mercancías extranjeras estuvieron sujetas a diferentes impuestos: $21 \%$ a la entrada en España; en las aduanas americanas, según lo establecido en el decreto de comercio libre de 1778, Almojarifazgo 7\%, Alcabala 3\%, Consulado 1\%. En abril de 1822, San Martín estableció el pago de un $20 \%$ sobre todos los géneros que ingresaran en buque extranjero, $18 \%$ sobre los productos que ingresaran en buque de Chile, Río de la Plata y Colombia, y el 16\% los buques peruanos, Mazzeo, 2003: 221. En julio de 1824, el virrey La Serna dio el Reglamento de Comercio Marítimo, por el que cobraría el 34\% por el Real Derecho de Alcabala, sobre las mercancías extranjeras, además del $6 \%$ de derecho de Consulado, 26 de noviembre de 1824 , ARAR, Intendencia, Administrativos, folio 108.

22 Informe presentado por el Prefecto de Arequipa don Francisco de Paula Otero, 29 de abril de 1825, Archivo General de la Nación (AGN), Sección Republicana, OL 131-181.

23 Obligación de Manuel Paredes a favor de don Lucas de la Cotera, 5 de agosto de 1822, ARAR, Protocolos, Nazario de Rivera, legajo 819, fol. 298; legajo 821, fol. 3. Protocolos, Matías Morales, legajo 746, fol. 558.

24 Witt, 1992: 35. 
cada miembro tuvo que desempeñar funciones específicas. Mientras Cotera se haría cargo de la búsqueda, adquisición y envío de todas las mercancías mencionadas en la constitución de la empresa, Murrieta se dedicaría únicamente a su comercialización en diversos mercados, debiendo para tal fin establecerse en «cualquier punto de Europa», con preferencia en el mercado de Londres ${ }^{25}$.

Sociedades mercantiles como la mencionada, con funciones complementarias entre sus miembros, fueron de importancia capital en esta época al asegurar la circulación natural de las mercancías hacia sus respectivos destinos, clave fundamental cuando se trataba de negocios a larga distancia. Dicha sociedad mancomunada recibió el nombre de «Cotera, Murrieta y Compañía» y todo indica que se mantuvo en vigencia hasta finalizar la guerra de Independencia. Al respecto, John Frederick Wibel, uno de los más entendidos en el tema de la economía y sociedad arequipeña de esta época y autor de una tesis imprescindible para conocer la evolución de la comunidad arequipeña entre la colonia y la república, nos manifiesta que se trató de la mayor empresa comercial establecida en Arequipa, desde la factoría de los Cinco Gremios Mayores de Madrid en el tardío siglo XVIII ${ }^{26}$.

El dinamismo en las actividades de Cotera, Murrieta y Compañía lo comprobamos a través de la abultada documentación almacenada en los archivos locales. Para muestra tenemos algunos ejemplos. En diciembre de 1822 Cotera envió desde el puerto de Quilca dos cargamentos de cacao de 45.000 y 37.500 libras respectivamente, en los navíos mercantes con bandera norteamericana Cantón y Gustavo, con destino a los puertos peninsulares de Cádiz y Santander; pagando por derechos de exportación en la aduana de Arequipa 34.379 pesos en total ${ }^{27}$. Al año siguiente, se remitieron nuevamente a la península, 39 pacas de lana de Vicuña «las mismas que se entregó a don Francisco Luciano Murrieta para su venta y enajenación», con un peso de 5.969 libras $^{28}$. En 1824,

25 Formación y establecimiento de una compañía de negocios, 20 de noviembre de 1822 , ARAR, Protocolos, Nazario de Rivera, legajo 820, fol. 411.

${ }^{26}$ La compañía de los Cinco Gremios Mayores de Madrid estableció un Almacén-Factoría en la ciudad de Arequipa en 1791 (junto con Veracruz y México, fue de las primeras establecidas en América). Aparentemente, el motivo para su instalación en esta no tan importante ciudad de provincia fue la posibilidad de controlar el comercio con el sur andino (lana y plata). No obstante, para principios del siglo XIX la compañía se encontraba en medio de una progresiva e irreversible crisis. El último apoderado de dicha casa fue el hacendado Luis Gamio (1818-1825), cuya principal función se limitó durante estos años al cobro de deudas por préstamos realizados anteriormente a los vecinos de la región. Véase al respecto ARAR, Intendencia, Causas Ordinarias, legajo 79. Causas Criminales, legajo 90. Wibel, 1975: 278.

27 ARAR, Caja Nacional de Hacienda, Libro Manual de 1822, fol. 91.

28 Declaración de don Lucas de la Cotera, 30 de agosto de 1827, ARAR, Protocolos, Manuel Primo de Luque, legajo 724, fol. 585. 
en sociedad con el destacado comerciante arequipeño Juan Mariano de Goyeneche, Cotera exportó a España un cargamento de lana de vicuña, cacao, estaño y bálsamo, por un valor de 63.700 pesos. Dicho cargamento fue recibido en Cádiz, siendo Murrieta nuevamente el encargado de su negociación ${ }^{29}$.

A propósito de las actividades de la compañía, no debemos perder de vista dos aspectos que consideramos relevantes. Por un lado, a pesar del ambiente de guerra continental que se vivía, el principal destino para tales mercancías seguía siendo la metrópoli española, a través de sus puertos de Cádiz y Santander, con los que algunas regiones de América continuaban manteniendo fuertes vínculos. Por el otro, los enormes cargamentos de cacao exportados a Europa desde los puertos arequipeños. Resulta obvio que tal mercancía no provenía de la región sur del virreinato, sino más bien del norte, específicamente de Guayaquil. Ya desde mediados del siglo XVIII la zona costera de Ecuador se había identificado por el cultivo de la «pepa de oro» o cacao, producto que en grandes volúmenes se exportaba desde el puerto de Guayaquil hacia el Virreinato del Perú, que servía momentáneamente de depósito hasta su reenvío final a los mercados europeos ${ }^{30}$. Como la guerra no había logrado interrumpir la producción y comercialización del cacao guayaquileño, la compañía Cotera-Murrieta continuaba abasteciéndose de este puerto. Así lo confirmamos en el contrato firmado en agosto de 1821 entre Francisco Luciano Murrieta y el capitán de la fragata Taiz «surta en el puerto de Mollendo de esta jurisdicción la cual debe ir a Guayaquil a cargar cacao para dirigirse a Cádiz» ${ }^{31}$.

Las especulaciones mercantiles en grandes volúmenes atendidas por Cotera le obligaban a asumir diversas responsabilidades y a entrar en conexión con numerosos representantes o apoderados no solo dentro del virreinato, sino también a lo largo de la ruta que unía la Intendencia de Arequipa con los «reinos de España». Gracias a ello pudo entretejer una vasta red de vínculos mercantiles y financieros que ampliaron el radio de sus intereses por una vasta región comprendida entre América y Europa. El método utilizado para este fin fue la entrega de poderes generales para «pedir, demandar, recibir y cobrar» en distintas ciudades como Cuzco, La Paz, Río de Janeiro, Cádiz, Londres y Bur$\operatorname{deos}^{32}$. Lamentablemente y muy a pesar suyo, algunos de sus apoderados no

29 Malamud, 1982: 120.

30 Acerca de la economía cacaotera ecuatoriana y sus vínculos con el virreinato peruano a fines del periodo colonial invitamos a revisar la tesis de Carlos Contreras «El sector exportador de una economía colonial. La costa del Ecuador entre 1760 y 1820», Lima, FLACSO, 1987.

31 Declaración de don Francisco Luciano Murrieta a favor del capitán Juan de Arrache, 21 de agosto de 1821, ARAR, Protocolos, Nazario de Rivera, legajo 819, fol. 294.

32 El número de poderes otorgados por Cotera entre 1821 y 1824 es bastante considerable 
siempre se condujeron al nivel de los requerimientos exigidos por el poderdante. Ese fue el caso, por ejemplo, de José Ventura Aguirresolarte, a quien Cotera en diciembre de 1821 había entregado un poder para que «recaude y reciba de todos los sujetos contra quienes le diera sus cartas y libranzas de todas las cantidades de dinero que ellas contuviesen» tanto en el puerto de Río de Janeiro como en la ciudad de Cádiz. Todo parece indicar que Aguirresolarte no cumplió efectivamente con este encargo, obligando años después a Cotera a entregar nuevos poderes a los señores Sampton, Batard y Compañía de Londres y asimismo a los señores de la Compañía de Burdeos.

Para que a su nombre puedan seguir y sigan con todo rigor de derecho a don José Ventura Aguirresolarte al pago de libranzas protestadas que ascienden la una a la cantidad de 25.000 pesos fuertes y la otra a 15.601 pesos $^{33}$.

\section{Relaciones con el Gobierno}

Los esfuerzos comerciales realizados por Cotera en medio de una situación económica tan favorable como la presentada en Arequipa durante esos años, le permitieron aumentar con creces sus ya enormes ingresos; sin embargo, como tales beneficios se obtenían dentro de un contexto de guerra y con un gobierno como el virreinal en estado frecuente de inanición por la falta de recursos bélicos y pecuniarios, su compromiso para el sostenimiento de este régimen debió ser mayor al de cualquier otro comerciante de la época. No debe sorprendernos entonces que en poco tiempo se haya convertido en el principal financista y abastecedor del gobierno español durante los años 1821-1824. Dicho compromiso se manifestó abiertamente a través de numerosas contribuciones monetarias, elevados préstamos «patrióticos» y espléndidos contratos para el abastecimiento del ejército real.

Las contribuciones monetarias fueron empréstitos forzados que las autoridades coloniales imponían a los principales vecinos y comerciantes de la región, según su posición social y capacidad económica. Tales exacciones de dinero se habían venido exigiendo a la comunidad arequipeña con cierta regularidad desde el levantamiento de Túpac Amaru a fines del siglo XVIII, pero a partir de la crisis de la monarquía española (1808) se hicieron mucho más frecuentes y con la llegada de las fuerzas chileno-argentinas de San Martín termi-

\footnotetext{
y se pueden hallar principalmente en ARAR, Protocolos, Nazario de Rivera, legajo 821, folios 61 y 225; legajo 822, folios 88 y 89. Manuel Primo de Luque, legajo 717, fol. 671; legajo 721 , fol. 848 .

33 Poder especial para cobrar. ARAR, Protocolos, Nazario de Rivera, legajo 822, folios 88 y 89 .
} 
naron siendo exasperantes para los golpeados vecinos de la Intendencia. John Wibel ha establecido a partir de su confiable estudio que, entre 1780 y 1814 , los arequipeños donaron más de 300.000 pesos y prestaron cerca de $100.000 \mathrm{a}$ fin de atender las continuas necesidades de la corona ${ }^{34}$.

Aunque los subsidios económicos de Cotera con el ejercito español venían desde muchos años atrás ${ }^{35}$, cuando era todavía vecino de La Paz y Potosí, en Arequipa sus contribuciones se iniciaron a partir del año 1822 y hasta finalizar el periodo virreinal, todos los montos entregados se encontrarán casi siempre entre los más altos del comercio de la ciudad y la propia Intendencia. Por ejemplo, en junio de 1822 del «contingente mensual» de 30.000 pesos exigidos a la provincia entregó primero 1.000 y luego 2.000, esta vez para completar los 60.000 pesos de préstamo requeridos de la Diputación Provincial ${ }^{36}$. En 1824 el virrey La Serna solicitó al comercio de la ciudad 28.269 pesos, correspondiéndole a Cotera 5.500, es decir, casi cuatro veces más que al segundo comerciante más rico de Arequipa, Ambrosio Ibáñez (1.600 pesos) e incluso estuvo muy por encima de todo el comercio de Arica (3.000 pesos) y la villa de Moquegua con $2.000^{37}$.

Por esta época se denominaban préstamos patrióticos desinteresados a aquellos socorros urgentes de dinero que ciertos acaudalados hombres de empresa y vecinos de la ciudad ofrecían voluntariamente, a fin de aliviar las apremiantes necesidades económicas del gobierno, sin intereses y sujetos a una pronta devolución. Con relación a ellos Cotera no tuvo rival. Horacio Villanueva Urteaga afirmaba que este «entusiasta realista» prestó a la Real Hacienda del Cuzco en 1823, primero 8.203 pesos y luego $15.000^{38}$. Tales montos, que en otras circunstancias hubiesen parecido considerables, palidecen si los comparamos con los préstamos realizados a la hacienda de Arequipa ${ }^{39}$. En ese

34 Wibel, 1975: 282.

35 Entre 1816 y 1818 Cotera suplió al ejército del Alto Perú diversas cantidades de dinero que luego le fueron reconocidas y canceladas por la Caja de Arequipa. ARAR, Caja Nacional de Hacienda, Libro Manual de 1816, fol. 91; Libro Manual de 1822, fol. 16.

36 ARAR, Caja Nacional de Hacienda, Libro Manual de 1822, folios 113-114.

37 ARAR, Caja Nacional de Hacienda, Libro Mayor de 1824, fol. 51.

38 Villanueva Urteaga, 1971: 36.

39 Comparando los montos entregados por Cotera y los exigidos en esa misma época por el gobierno de San Martín al comercio de Lima, ellos siguen siendo bastante considerables. En el empréstito de enero de 1822, por 72.000 pesos exigidos a los comerciantes ingleses, Juan Beggs y Cía. entregó 12.000 pesos; Templeman Bergman y Cía. 7.000; Juan Parish Robertson 6.000; Guillermo May 3.500 y Diego Goldie 2.500 pesos fuertes. De la lista de españoles que el gobierno presentó en abril de 1823 al Consulado de Lima, para un empréstito de 70.000 pesos, Francisco Javier de Izque aportó 4.000 pesos; Pedro Villacampa y Manuel Gorbea 3.000; Dámaso Arias 2.000; Andrés Reboredo y Antonio Sáenz 1.250 pesos cada uno. Mazzeo, 2006: 69-70. 
mismo año de 1823 , cuando ya se hallaba bien consolidado dentro de la región, entregó voluntariamente 63.000 pesos y en 1824, primero 40.000 y luego 51.354 pesos; este último, destinado al flete del navío llamado Tetis, que fue enviado a la península con "pliegos interesantes del servicio». De este modo, al finalizar el gobierno virreinal, contando los créditos mencionados y otros préstamos más, Cotera llegó a acumular servicios a su favor por un monto de 369.644 pesos, que «en la real hacienda de esta ciudad se han abonado al comerciante don Lucas de la Cotera, por cuenta de los créditos que reconoce la real hacienda a su favor» ${ }^{40}$.

Como se ha señalado, las contribuciones y préstamos pecuniarios no representaron las únicas modalidades de sostener al régimen colonial en el Perú, además de ellas estuvieron los contratos para el abastecimiento del ejército realista con armas, uniformes y demás pertrechos de guerra. Meses antes de establecer su residencia en la ciudad de Arequipa, Cotera había recibido un oficio del virrey La Serna solicitándole «un particular y extraordinario servicio» para la compra de miles de fusiles y sables de algunos de los numerosos barcos extranjeros que recorrían las costas de la Intendencia. Al no encontrar semejante cargamento, Cotera planteó una nueva propuesta a las autoridades españolas: negociar tales suministros en ciertos países de Europa. Con este objetivo, en noviembre de 1821, firmó un contrato con la Real Hacienda de Arequipa a fin de proveer al ejército virreinal con 6.000 fusiles, 20.000 uniformes, 4.000 sables de caballería, 6.000 pesos en medicina y hasta una imprenta; en un plazo no menor de cinco meses para las armas, ni mayor a once para lo restante. Acerca de la forma de pago, como la hacienda real carecía de los fondos suficientes para cubrir tan abultada suma (aproximadamente 180.000 pesos), la única forma de cancelación posible se haría «descontando de los derechos (de importación) que fuera adeudando por las embarcaciones que vinieran a su consignación desde Europa» ${ }^{41}$. Para el cumplimiento del contrato, Cotera encomendó la misión de adquirir tales armas en Europa a su socio Francisco Luciano Murrieta.

Antes de finalizar este segmento sobre sus relaciones con el gobierno virreinal, queremos resaltar del contrato anterior un punto que nos ha parecido revelador acerca de sus actividades económicas y del cuasi monopólico dominio que tuvo de las importaciones. El punto gira en torno a las deudas contraídas por la Hacienda Nacional, sea a través de préstamos patrióticos o contratos

\footnotetext{
40 ARAR, Caja Nacional de Hacienda, Libro Mayor de 1824, fol. 116-125.

41 Contrata entre el comerciante Lucas de la Cotera con los señores ministros principales de la hacienda pública de estas cajas nacionales, 24 de noviembre de 1821, ARAR, Protocolos, Manuel Primo de Luque, legajo 717, fol. 630.
} 
de abastecimiento, los que no eran abonados en efectivo, sino a través de la concesión de numerosos privilegios y exoneraciones arancelarias. Porque fue precisamente a través de ellas que Cotera pudo controlar casi en su totalidad el comercio extranjero e importar millones de pesos en mercancías sin pagar un solo real por concepto de derechos aduaneros. Así lo manifiesta el propio comerciante en una nota remitida al administrador de la aduana de Arequipa, en noviembre de 1824 .

En oficio del 19 del presente del que rige, he recibido la planilla general de los derechos que adeudan los cargamentos internados a mi consignación. El bergantín Swallon se halla entre ellos y estando destinado este buque a uno de mis permisos, según consta del expediente que se esta siguiendo, se ha de servir V. excluirlo de la liquidación general ${ }^{42}$.

Tales permisos o exoneraciones fiscales estuvieron rigurosamente destinados a un número determinado de embarcaciones, previamente señaladas por las autoridades aduaneras; en consecuencia, no se trató de una suerte de «patente de corso» para importar libremente de cuanto navío se encontrase anclado en algún puerto o caleta de la extensa costa arequipeña. A pesar de dichas limitaciones, Cotera no siempre actuó con la transparencia y honestidad que se podría suponer en un empresario tan poderoso y privilegiado. En asociación con otros comerciantes, recibió algunas consignaciones extranjeras sin poseer los documentos requeridos o las «notas», como se decía entonces, que eran imprescindibles para la realización de tal actividad. Ese fue el motivo que llevó en noviembre de 1824 a Narciso Benavides, administrador de la Real Hacienda de Arequipa, a exigirle la presentación de dichas notas para sustentar las consignaciones recibidas. Al no producirse contestación alguna, un mes después, José María Sánchez Chávez, ministro tesorero general de la Real Hacienda y comisionado por el gobierno de la Intendencia de Arequipa, ordenó:

A los comerciantes don Lucas de la Cotera, don Ambrosio Ibáñez, don Guillermo Hodgson y don Santiago Ygualt cumplan con lo mandado en el decreto expedido por la administración de la aduana de esta ciudad en 20 del anterior, según el artículo 20 del Reglamento de Comercio Marítimo, en el concepto de no hacerlo así se les formará el correspondiente cargo por aquella con arreglo a los avalúos que se han tomado de sus respectivas negociaciones para la satisfacción de los derechos de entrada ${ }^{43}$.

42 Oficio al señor Administrador de esta Aduana, 26 de noviembre de 1824, ARAR Intendencia, Causas Administrativas, legajo 108.

43 Sobre presentación de notas por don Lucas de la Cotera, don Ambrosio Ibáñez, don Guillermo Hodgson y don Santiago Ygualt, 6 de diciembre de 1824, ARAR Intendencia, Causas Administrativas, legajo 108. 


\section{Actividades sociales}

A mediados del siglo XVIII las colonias americanas se vieron masivamente «invadidas» por miles de peninsulares provenientes principalmente de las regiones vascas, atraídos por la posibilidad de realizar grandes negocios y favorecidos por las reformas que durante esos años se experimentaban en el Imperio Español ${ }^{44}$. Jóvenes en su mayoría, se avecindaron en las principales ciudades americanas, empleándose en el lucrativo negocio de las importaciones de efectos desde España, para lo cual aprovecharon sus fuertes vínculos comerciales con influyentes compañías gaditanas y una coyuntura propicia generada por el establecimiento del Comercio Libre (1778). A fin de consolidarse al interior de las respectivas sociedades locales, muchos de ellos buscaron matrimoniarse ventajosamente con damas pertenecientes a reconocidas familias criollas. Ese fue el caso en Arequipa, de Juan Crisóstomo de Goyeneche y Aguerreverre, Mateo Cossío de la Pedrera, Antonio Alvisuri y Sagasti, Juan Fermín de Errea, entre otros ${ }^{45}$. Todos ellos migrantes que en pocos años habían logrado posicionarse social y económicamente en toda la región.

Cuando a mediados de 1821 se presentó una nueva avalancha de comerciantes limeños, peninsulares y extranjeros, la elite arequipeña ya estaba bastante familiarizada con este tipo de migraciones y hasta cierto punto eran bien recibidas, en razón a las grandes posibilidades de nuevos negocios que podían atraer a la región; con este fin, no desaprovechaban oportunidad alguna para incorporarlos al interior de sus exclusivas familias. Son explicables entonces, las expresiones del viajero inglés Samuel Haigh, quien después de visitar la ciudad en 1825 afirmaba que cerca de la mitad de los veinte ingleses residentes en Arequipa «se habían casado o comprometido con damas arequipeñas ${ }^{46}$. Contrariamente a lo descrito, en los casi tres años que Cotera residió en la ciudad no contrajo matrimonio alguno ni buscó relacionarse parentalmente con ninguna de las muchas familias de la elite local y sus acercamientos, cuando los hubo, estuvieron reducidos a niveles básicamente económicos.

Tales acercamientos con la aristocracia arequipeña le permitieron consolidarse al interior de la sociedad local y uno de los medios empleados para alcanzar este fin fue el otorgamiento de fianzas. La fianza era un monto de dinero exigido por las autoridades coloniales en garantía de las obligaciones finan-

44 Buller, 1988: 106.

45 Testamento de Juan Crisóstomo Goyeneche, 24 de setiembre de 1813, ARAR, Protocolos, Nazario de Rivera, legajo 816, fol. 5. Wibel, 1975: 87-105. Brown, 1985: 105-106.

46 Haigh, 1967: 23-50. 
cieras relacionadas a ciertos funcionarios, como, por ejemplo, los encargados de la recaudación del tributo o el diezmo y que debía pagarse antes de comenzar dichas actividades. Como la mayoría de los montos exigidos ascendían a varios miles de pesos, era comprensible que muy pocos individuos estuvieran en condiciones de garantizarlos, por ello los potenciales funcionarios recurrían a miembros del comercio local, entre los que se encontraba don Lucas de la Cotera $^{47}$. En tal sentido, en agosto de 1821, contribuyó con 2.000 pesos para completar los 8.000 exigidos a don Toribio Antonio Infiesta antes de ocupar el cargo de Contador de las Cajas Reales de la ciudad de Tacna ${ }^{48}$; en abril de 1823, entregó la misma cantidad a favor de don José Borbón, subdelegado electo del partido de Tarapacá, por los 10.500 pesos requeridos ${ }^{49}$, y en enero de 1824, dio una fianza de 22.000 pesos a nombre de don Manuel José Tovar, a fin de que este pudiera asumir el cargo de subdelegado en el lejano partido de Poopó ${ }^{50}$. Junto con las fianzas, Cotera pudo vincularse con algunos miembros prominentes de la comunidad arequipeña a través de la conocida entrega de poderes para «pedir, demandar, recibir y cobrar» a ciertos individuos de dentro y fuera de la región. Al tener como sus principales garantías el enorme poder económico, la extensión de sus actividades y el ascendiente que guardaba entre las autoridades españolas, es fácil darse cuenta de por qué fue tenido como el apoderado «favorito» de numerosos vecinos y residentes de la localidad, nacionales y extranjeros ${ }^{51}$.

Todas estas conexiones sobradamente demostradas con miembros de la elite local y construidas a través de medios tan disímiles, le permitieron a Cotera actuar como intermediario en la adquisición de propiedades rurales pertenecientes al Estado colonial y a nombre de influyentes vecinos como los Gamio, Goyeneche y Fernández Arredondo. En octubre de 1823, una superior orden del gobierno virreinal dispuso que se vendieran en público remate «todos los

47 En enero de 1825, Matías Agois pagó 16.771 pesos por ocupar la Intendencia de Arica, y en marzo, Mariano Basilio de la Fuente, 26.000 pesos por la Intendencia de Moquegua. ARAR, Protocolos, Manuel Primo de Luque, legajo 722, folios 107 y 171.

48 Fianza por el contador de cajas reales de Tacna don Toribio Antonio de Infiesta, 22 de agosto de 1821, ARAR, Protocolos, Manuel Primo de Luque, legajo 717, fol. 257.

49 Fianza por el Teniente Coronel don José Borbón, subdelegado del partido de Tarapacá, 26 de abril de 1823, ARAR, Protocolos, Manuel Primo de Luque, legajo 720, fol. 705.

50 Fianza de 22.000 pesos. Don Lucas de la Cotera vecino y del comercio de esta ciudad a favor de la hacienda nacional por don Manuel José Tovar vecino de la villa de Oruro, 16 de enero de 1824, ARAR, Protocolos, Nazario de Rivera, legajo 822, fol. 23.

51 Poder para varios efectos. ARAR, Protocolos, Manuel Primo de Luque: 718, fol. 256; legajo 721, folios 520 y 947. Nazario de Rivera, legajo 820, folios 67 y 122; legajo 822, fol. 315 . 
bienes raíces del extinguido colegio de la Buena Muerte» ${ }^{52}$ y las tierras sobrantes de los alrededores de la ciudad, a fin de «auxiliar con su producto, las enormes urgencias del ejército nacional ${ }^{53}$. De este modo, entre enero y marzo de 1824, adquirió cinco propiedades rurales en los suburbios de Arequipa por un valor total de 112.300 pesos, «presentando dicho don Lucas de la Cotera a su señoría un escrito declarando que el remate había sido» para doña María de la Presentación de Goyeneche y Barreda ${ }^{54}$, don Bernardo Gamio ${ }^{55}$ y don Manuel Fernández Arredondo ${ }^{56}$.

En resumidas cuentas, el obrar como fiador para la obtención de cargos públicos, recibir poderes de importantes vecinos y comerciantes o servir como intermediario en la adquisición de propiedades para terceros, son una garantía para las buenas relaciones de cualquier individuo dentro de una sociedad de la cual no ha sido parte. Pero Cotera al parecer fue un poco más lejos, al organizar excursiones veraniegas para familias enteras de la elite arequipeña en balnearios cercanos a la ciudad. Así lo testimonia el viajero alemán Heinrich Witt, quien en setiembre de 1824 observó en la caleta de Quilca «algunas carpas dispersas por el vecindario, ocupadas por alrededor de cuarenta hombres y mujeres», quienes habían llegado con el propósito de vacacionar, y según se le manifestó todos «los gastos corrían por cuenta de don Lucas de la Cotera» ${ }^{57}$.

\section{Ocaso de sus actividades}

Para 1824 el prestigio de Cotera había rebasado los límites del territorio controlado por las fuerzas realistas (sur del Perú y Alto Perú) y ante los ojos de la dirigencia patriota se visualizaba como una fuente incalculable de recursos materiales y monetarios que se podía aprovechar para el mantenimiento de las

52 Venta de una chacra que fue del extinguido colegio de la Buena Muerte, 14 de febrero de 1824, ARAR, Protocolos, Manuel Primo de Luque, legajo 721, fol. 207.

53 AMA, Libro de Actas del Cabildo, libro 29, sesión del 16 de octubre de 1823.

54 Remate. Presentó dicho don Lucas de la Cotera a su señoría un escrito declarando que el remate había sido para la señora doña María de Goyeneche, a cuyo favor debía otorgar la escritura, 14 de febrero de 1824, ARAR, Protocolos, Manuel Primo de Luque, legajo 721, fol. 207.

55 Venta de chacra que fue del extinguido colegio de la Buena Muerte al señor Capitán don Bernardo Gamio a través de don Lucas de la Cotera, 22 de febrero de 1824, ARAR, Protocolos, Manuel Primo de Luque, legajo 721, fol. 134.

56 Remate. Se remató en don Lucas de la Cotera, quien declaró había sido para el señor Manuel Fernández Arredondo, 17 de marzo de 1824, ARAR, Protocolos, Manuel Primo de Luque, legajo 721, fol. 315.

57 Witt, 1992: 35. 
fuerzas libertadoras ${ }^{58}$. Muy consciente de su delicada posición, durante la invasión colombiana de la ciudad de Arequipa en agosto de 1823, tomó la acertada decisión de ponerse a buen recaudo, refugiándose en la fragata extranjera Florinda, anclada en el puerto de Quilca ${ }^{59}$. Se trató de una medida muy segura y sobre todo correcta. En los 39 días que duró la desgraciada ocupación patriota dirigida por el general Sucre, fueron los vecinos notables los que padecieron las mayores contribuciones, confiscaciones y saqueos. Como era de esperarse, la más perjudicada fue la acaudalada familia Goyeneche, quienes como consecuencia de la invasión vieron mermada su fortuna en 80.000 pesos $^{60}$. Concluido aquel luctuoso episodio, Cotera comprendió muy bien la necesidad de mantener buenas relaciones ya no solo dentro del bando realista, sino también, en el patriota, a fin no solo de preservar sus enormes inversiones en la región, sino también, de asegurarse para el futuro potenciales servicios. Con este objetivo, en setiembre de 1824 otorgó una fianza a favor de don Francisco Basadre, teniente coronel de los ejércitos patriotas, para que pueda regresar al «seno de su casa»; constituyéndose el propio Cotera en «fiador de abono de la conducta y comportamiento del expresado Francisco Basadre» ${ }^{61}$. Ese mismo año, intercedió personalmente ante las autoridades virreinales por la liberación del reconocido patriota y hacendado Manuel Amat y León, quien fue apresado por los realistas durante la última ocupación de Lima ocurrida en febrero de $1824^{62}$.

Pero de nada le sirvió este forzado oportunismo político. Después de la derrota definitiva del ejército español en los campos de Ayacucho en diciembre de 1824, Cotera tuvo que abandonar apresuradamente el Perú ${ }^{63}$. Consultada la numerosa documentación de la época, notamos que esta fue una decisión de último momento, en vista que sus actividades previas —al menos ese año-

58 En diciembre de 1825 Simón Bolívar ordenó que el comerciante inglés Santiago Ygualt, apoderado de don Lucas de la Cotera, «tiene que entregar a la prefectura -Arequipa - 25.000 que le exigen ahora a cuenta del tanto por ciento que tiene que pagar sobre las cobranzas de Cotera», Bolívar, 1950: 288-290.

59 Poder para cobranzas y pleitos. Don Juan Bautista Detroyat residente en esta y del comercio de Burdeos, 20 de setiembre de 1823, ARAR, Protocolos, Manuel Primo de Luque, legajo 720 . fol. 923 .

60 Malamud, 1982: 108.

61 Fianza de abono. Don Lucas de la Cotera por don Francisco Basadre Teniente Coronel que fue del ejército de la patria, 30 de setiembre de 1824, ARAR, Protocolos, Manuel Primo de Luque, legajo 721, fol. 813.

62 Peraltilla, 1971: 58.

63 Poder especial para cobranza. A don Lucas de la Cotera próximo a ausentarse a los reinos de España, 28 de diciembre de 1824, ARAR, Protocolos, Nazario de Rivera, legajo 822, fol. 315 . 
no muestran intención alguna de alejarse de la región. En abril de 1824, compró a Leonardo Sester, vecino y del comercio de los Estados Unidos una goleta nombrada Adonis que se hallaba fondeada en el puerto de Quilca, por 1.500 pesos al contado ${ }^{64}$; en mayo arrendó una casa-vivienda en 1.200 pesos anuales «por el tiempo que tuviese a bien ocuparla»" ${ }^{65} \mathrm{y}$, en agosto de ese mismo año, otra propiedad a doña María Mercedes Moscoso, madre del brigadier y último virrey del Perú Pío Tristán, por el término de seis años ${ }^{66}$. Antes de su inminente partida, buscó cobrar sus mayores deudas principalmente con la Caja Nacional de Hacienda, de la que recibió los ya mencionados 369.644 pesos. Para las restantes, así como para la administración de sus diversos intereses en la ciudad, entregó numerosos poderes a reconocidos comerciantes extranjeros y de la localidad, como José Genaro de la Torre, Guillermo Cochran y Santiago Ygualt ${ }^{67}$. El 3 de enero de 1825 se embarcó en el puerto de Quilca a bordo de la fragata francesa Ernestine, junto a reconocidos personajes del fenecido régimen virreinal, entre los que se encontraban el virrey La Serna, los generales Valdés y Villalobos, los brigadieres Landázuri y Ferraz, el administrador de la aduana de Arequipa, el coronel Santa Cruz, el medico-cirujano Ángel Miner «y algún otro de los que pudieron aprontar mil duros por persona de primera mesa y cuatrocientos por cada sirviente o criado» ${ }^{68}$.

\section{DESPUES DE LA GUERRA}

La Independencia fue jurada definitivamente en la ciudad de Arequipa a principios de 1825 y aceptada como un hecho consumado por la mayoría de sus vecinos. Lo paradójico de ello fue que la nueva situación no representó alivio alguno para la deprimida economía regional. La crisis minera siguió acentuándose aún más, no obstante los esfuerzos de algunos vecinos por recuperar-

64 Venta de una goleta llamada Adonis. Don Leonardo Sester vecino y del comercio de Estados Unidos, 25 de abril de 1824, ARAR, Protocolos, Nazario de Rivera, legajo 822, fol. 113.

65 Arrendamiento de casa. Don José Mariano y don Sebastián de la Llosa a favor de don Lucas de la Cotera del comercio de esta ciudad, 8 de mayo de 1824, ARAR, Protocolos, Manuel Primo de Luque, legajo 721, fol. 536.

66 Arrendamiento de casa. Doña María Mercedes Moscoso al señor don Lucas de la Cotera de este comercio, 25 de agosto de 1824, ARAR, Protocolos, Manuel Primo de Luque, legajo 721 , fol. 763 .

67 Poder general. ARAR, Protocolos, Manuel Primo de Luque, legajo 721, fol. 947; legajo 722, fol. 822. Nazario de Rivera, legajo 822, fol. 290.

68 García Camba, 1846: 276-279. Wagner de Reyna: 1985: 37-59. 
la con ayuda de capitales extranjeros. En julio de 1825 se formó una compañía minera entre la más rica familia de Tarapacá, los de la Fuente Loayza, y el comerciante inglés Guillermo Hodgson, para el trabajo de «varias minas de plata citas en el mineral y cerro de San Agustín de Huantajaya por 15 años ${ }^{69}$. Asimismo, en septiembre de ese año se estableció otra compañía minera entre Santiago Ygualt, Samuel Haigh, Roberto Page, Tomas Crompton, José María Martínez y Atanasio Hernández, con un fondo de 100.000 pesos, con el objetivo de comprar o arrendar minas de oro, plata y cobre en las provincias de Puno, La Paz y Oruro $^{70}$. Lastimosamente, tales inversiones no fueron suficientes para derrotar los tradicionales obstáculos de la minería colonial arequipeña: falta de mano de obra y capitales, además de los altos costos de los suministros, dinamita y azogue. Corroborando tan dramática situación, en 1826, el subdirector general de Minería culpaba a la «suma escasez de pólvora y azogue en aquel departamento», por no favorecer los esfuerzos de expansión minera y debido a ello esta industria se hundía «en la mayor languidez, sin producir por consiguiente todo el producto de que es susceptible» ${ }^{71}$.

La industria vinatera enfrentó durante los primeros años de vida autónoma similares dificultades a las encontradas por la minería local, tanto así, que la coyuntura depresiva iniciada en tiempos de guerra, antes que detenerse, se fue acentuando dramáticamente hasta llegar al colapso definitivo a mediados del siglo XIX. Para crearnos una imagen global de la producción de los tres principales valles después de la independencia, recurrimos nuevamente a las estadísticas.

Los números nos hablan de una verdadera catástrofe productiva durante estos años, que incluso fue mayor a la experimentada durante la guerra de la Independencia (Cuadro 4). Acerca de las razones, un trabajo anterior nos permitió aproximarnos a algunas de las causas de este colapso. a) La destrucción ocasionada por las guerras de Independencia en los principales mercados mineros del sur del Perú y Bolivia; b) La escasez crónica de trabajadores, motivada por las continuas guerras civiles de principios de la era republicana; c) La falta de mulas y el alto costo del transporte; d) La creación de Bolivia, que significó el cierre del más importante mercado para los vinos y aguardientes; e) La competencia de nuevos licores finos provenientes de Europa y de aque-

69 Compañía con tiempo. Don Francisco de la Fuente Loayza con don Guillermo Hodgson. ARAR, Protocolos, Rafael Hurtado, legajo 675, folios 257 y 335. Protocolos, Manuel Primo de Luque, legajo 722, fol. 587. También revisar Haigh, 1967: 22. Wibel, 1975: 375.

70 Compañía para el trabajo y ramo de minería. ARAR, Protocolos, Matías Morales, legajo 749 , fol. 343 .

71 Deustua, 1986: 85. 
Cuadro 5. Producción de VINOS EN AREQuiPa 1825-1830

(en botijas)

\begin{tabular}{|c|c|c|c|}
\hline Años & Vítor & Majes & Moquegua \\
\hline 1825 & 73.280 & 70.925 & 175.230 \\
1826 & 75.245 & 45.745 & 184.450 \\
1827 & 61.845 & 58.875 & 192.685 \\
1828 & 57.275 & 52.560 & 161.785 \\
1829 & 34.805 & 39.225 & 124.810 \\
\hline
\end{tabular}

Fuente: AAA, Diezmos de los valles de Vítor, Majes y Moquegua.

llos aguardientes de caña producidos en Bolivia y Perú; y f) La falta de innovación de los viñateros locales, quienes durante más de un siglo se habían habituado a destilar aguardientes y transportarlos al altiplano. Frente a una nueva realidad, tuvieron muy poca inclinación a cambiar de cultivos o a mejorar la producción de los mismos para hacerla más competitiva. Ello muy a pesar de las magníficas condiciones climáticas y edafológicas de la región, que permitían la producción de hasta 18 variedades de uva ${ }^{72}$.

Comercialmente, la independencia conllevó la ruptura definitiva del monopolio español y la apertura del país y la región a los negociantes europeos, principalmente ingleses y franceses. En este sentido, únicamente las importaciones británicas al Perú pasaron de 199.000 libras esterlinas, en 1826, a 368.000 , en $1830^{73}$. Mientras, en Arequipa, tales inversiones alcanzaban los tres millones de pesos solo en créditos y propiedades en $1824^{74}$. Un año después, ya se encontraban instaladas 16 casas comerciales extranjeras, las que progresivamente fueron desplazando a los grandes mercaderes peninsulares y criollos. Las compañías comerciales más destacadas en estos primeros años fueron las de Gibbs-Crawley, Dickson-Price, Tayleur-Mac Laughlin, Jack Hermanos, Willie-Miller, Begg-Athenton, Santiago Le Bris, Daniel y Cristóbal Guillermo Schutt, entre otras ${ }^{75}$. Con la apertura del puerto de Islay (1827), en reemplazo de la incómoda e incompatible caleta de Quilca, los volúmenes de mercancías europeas, principalmente tejidos, se multiplicaron considerablemente hasta superar con exceso la demanda local provocando como consecuencia, el quiebre de numerosos comercios y una incontenible caída en

72 Condori, 2010: 54-60

73 Gootenberg, 1997: 319. Bonilla, 1981: 110.

74 Wibel, 1975: 364.

75 ARAR, Libros de la Tesorería de Arequipa 1827-1830. Witt, 1992: 60-69. Wibel, 1975: 368-375. 
los precios, tanto así, que hasta los negros más pobres podían vestirse con textiles importados ${ }^{76}$. Confirmando lo antedicho, el cónsul británico en el Perú, Charles Milner Ricketts, señalaba en 1826 «el espíritu de especulación, y las descripciones exageradas de la riqueza en el Perú, condujeron a la consignación de muchos barcos con cargamentos que excedían largamente las necesidades del público y su capacidad de pago» ${ }^{77}$. Mucho más dramático es el informe de 1834 del Cónsul General de Gran Bretaña en el Perú, Belford Hinton Wilson, acerca del mismo asunto.

En el año 1825 y los dos años siguientes, Perú fue inundado con productos extranjeros. Este exceso de oferta produjo una necesidad de confiar en los compradores sin la debida precaución, y este sistema fue llevado a tal extremo que, difícilmente se exigía otra calificación que aquella que ser originario del país. Pronto aparecieron las consecuencias naturales de esta confianza mal fundada, los bienes de este modo vendidos imprudentemente al crédito, nunca fueron pagados, y ninguna ganancia se pudo enviar a Inglaterra ${ }^{78}$.

Con respecto a nuestro conocido, el comerciante español Lucas de la Cotera, si su destino final era la Madre Patria nunca llegaría a ella. En marzo de 1826 se hallaba bien establecido en Río de Janeiro y dedicado a la filantropía, ayudando a los que no tenían medios para continuar su viaje o mantenerse en la capital brasileña. Así nos lo testimonia el general Guillermo Miller, quien de regreso a Inglaterra lo visitó en dicha ciudad y nos refiere que «aunque su fortuna había sufrido considerablemente, mantenía con la que le quedaba a más de veinte desterrados que no tenían un real, tanto españoles como peruanos, y para cuyo objeto había tomado una casa espaciosa, donde vivían todos juntos $\gg^{79}$. Un año después, se hallaba de vuelta en Bolivia, y gracias a sus buenas relaciones con el recién inaugurado gobierno del mariscal Antonio José de Sucre ${ }^{80}$, en marzo de 1827 «el gobierno autorizó a de la Cotera a establecer, mediante sus agentes, un puesto comercial en Cobija y explorar la mejor ruta hacia el interior $\rangle^{81}$. Numerosos testimonios nos indican que su participación en el desarrollo del puerto de Cobija o La Mar, durante el gobierno de Sucre,

76 Wibel, 1975: 365. Gootenberg, 1990: 1-56.

77 Bonilla, 1975: 23.

78 Ibidem: 88-89.

79 Miller, 1975: 306

80 El 10 de noviembre de 1829 Sucre redactó su testamento en Quito. Entre sus numerosos bienes dejaba «12.000 pesos en plata que tengo en poder de don Lucas de la Cotera, residente en Bolivia, y cuya obligación se halla entre mis papeles». Gonzales Paredes, 2006: 281-282.

81 Lofstrom, 1987: 365 
fue de capital importancia; y así lo confirma Fernando Cajías en su estudio sobre la provincia de Atacama.

Con la ayuda del comerciante español Lucas de la Cotera, el primer cargamento importante que se internó por La Mar era un pedido del gobierno boliviano consistente en paños para uniformes del ejército y armamento destinado a las plazas de Oruro, Potosí y Tarija ${ }^{82}$.

Al retirarse de Arequipa en enero de 1825, Cotera dejó como su representante legal al comerciante inglés Santiago Ygualt, quien durante los años 1826 y 1827 se encargó de la administración de todos sus negocios, así como el cobro de sus numerosas deudas en la región y Lima. A principios de 1827, se encontraba nuevamente en suelo arequipeño y frente a una realidad diferente a la dejada hacía solo dos años. Por ello, ya no volvería a ser el gran importador de mercancías que fue, ese lugar ahora le correspondía al gremio de los grandes comerciantes extranjeros; su labor más bien consistirá en finiquitar todos los negocios posibles entregando poderes para que «pidan, demanden, reciban y cobren» a los señores Francisco Castañares, de próxima partida a Europa; don Santiago Portu, residente en Potosí; don José María Valle, de viaje rumbo a la villa de Tacna, y don Francisco Antonio Larraza, del comercio de Cádiz. Cobrando además viejas deudas a don Isidoro Quezada, por 1.068 pesos; don Pablo Idiáquez, por 2.500, y don Jorge Filinichi, por 5.969 pesos. Para lo restante, en diciembre de 1827 hará una cesión de todos sus créditos activos «con autorización bastante y con la rebaja de un $25 \%$, siendo de cuenta de los compradores los resultados de la cobranza», a favor de la casa francesa de los señores Le Bris y Bertheaume, que en documentos, conciliaciones y letras ascendían a la suma de 127.085 pesos $^{83}$. Finalmente, después de tantos años, sus vínculos económicos y políticos con Arequipa habían llegado a su fin, aunque como todo buen empresario capitalista, ellos proseguirían en un nuevo escenario como el boliviano, esta vez al servicio de los intereses de una nueva causa.

\section{ARCHIVOS}

Archivo Arzobispal de Arequipa (AAA). Causas Civiles, Diezmos.

Archivo Municipal de Arequipa (AMA). Libro de Actas del Cabildo.

Archivo Regional de Arequipa (ARAR). Protocolos, Libros de Hacienda, Intendencia.

82 Cajías de la Vega, 1975: 256.

83 Acerca de las actividades de Lucas de la Cotera y sus apoderados en Arequipa entre 1826, 1827 y 1829 en ARAR, Protocolos, Manuel Primo de Luque, legajo 723, folios 125-818; legajo 724, folios 13-899. Protocolos, Mariano Arnillas, legajo 473, folios 275-287. 


\section{BIBLIOGRAFÍA}

Barriga, Víctor, Memorias para la Historia de Arequipa, tomo I, Arequipa, Editorial La Colmena, 1941.

Bolívar, Simón, Obras Completas, vol. 2, La Habana, Editorial LEX, 1950.

Bonilla, Heraclio (comp.), Gran Bretaña y el Perú 1826-1919: Informes de los cónsules británicos, vol. I, Lima, Instituto de Estudios Peruanos, 1975.

Bonilla, Heraclio y Spalding, Karen, La Independencia en el Perú, Lima, Instituto de Estudios Peruanos, 1981.

Brading, David, Mineros y comerciantes en el México borbónico (1763-1810), México, FCE, 1985.

Brown, Kendall, «Movimientos de precios en Arequipa, Perú, en el siglo XVIII», Lyman Johnson y Enrique Tandeter (comp.), Economías Coloniales. Precios y Salarios en América Latina, siglo XVIII.

Brown, Kendall, Borbones y aguardiente. La reforma imperial en el sur andino: Arequipa en vísperas de la Independencia, Lima, Instituto de Estudios Peruanos, 2008.

Buller, Carlos, «Peninsulares y Criollos: el surgimiento de una elite comercial importadora en Arequipa durante el tardío siglo XVIII», Tesis de Bachiller, Lima, Pontificia Universidad Católica del Perú, 1988.

Buller, Carlos, «La producción agrícola no especializada en vino de Arequipa (1772-1830)», Histórica, XXXI / 2 (Lima, 2007): 69-113.

Buller, Carlos, «L'économie du vin à Arequipa. Les vallées de Vitor, Majes et Moquegua entre 1770 et 1850», Nuevo Mundo Mundos Nuevos, Aula virtual, 2009, [En línea], Puesto en línea el 06 de julio de 2009. URL: http://nuevomundo.revues.org/ 56470 .

Cajías de la Vega, Fernando, La Provincia de Atacama, 1825-1842, La Paz, Instituto Boliviano de Cultura, 1975.

Condori, Víctor, «Lucas de la Cotera: Financista del gobierno virreinal, 1821-1824», Historia, 8 (Arequipa, 2006): 109-123.

Condori, Víctor, «El vino en Arequipa colonial», Boletín de Lima, XXXII / 159 (Lima, 2010a): 54-60.

Condori, Víctor, «Los efectos económicos de la Independencia en Arequipa: 1820-1824», Carlos Contreras, Cristina Mazzeo y Francisco Quiroz (ed.), Guerra, finanzas y regiones en la historia económica del Perú, Lima, Instituto de Estudios Peruanos, 2010b: 173-218.

Condori, Víctor, «Sociedad, identidad y regionalismo en Arequipa, 1780-1830», Historia, 9 (Arequipa, 2010c): 47-71. 
Contreras, Carlos, «El sector exportador de una economía colonial. La costa del Ecuador entre 1760 y 1820», Tesis de Maestro en Ciencias Sociales, Lima, FLACSO, 1987.

Chambers, Sarah, «Los matices de la Ciudad Blanca: La cultura y sociedad urbana de Arequipa, Perú, 1780-1854», Revista de Ciencias Sociales, 3 (Arequipa, 1997): 241-281.

Chambers, Sarah, De súbditos a ciudadanos: honor, política y género en Arequipa, 1780-1854, Lima, La Red, 2003.

Davies, Keith, «The Rural Domain of the City of Arequipa, 1540-1665», Tesis de Doctorado, Universidad de Connecticut, 1974.

Davies, Keith, «La tenencia de la tierra en Arequipa colonial: 1540-1650», Historia, 1 (Arequipa, 1975): 29-46.

Davies, Keith, Landowners in Colonial Peru, Austin, University of Texas Press, 1984.

Deustua, José, La minería peruana y la iniciación de la república, 1820-1840, Lima, Instituto de Estudios Peruanos, 1986.

Fisher, John, Minas y mineros del Perú colonial: 1776-1824, Lima, Instituto de Estudios Peruanos, 1977.

Fisher, John, Gobierno y sociedad en el Perú colonial. El régimen de la Intendencia, 1784-1814, Lima, Pontificia Universidad Católica del Perú, 1981.

Flores Guzmán, Ramiro, «E1 Tribunal del Consulado de Lima frente a la crisis del estado borbónico y la quiebra del sistema mercantil (1796-1821)», Scarlett O'Phelan Godoy (comp.), La Independencia del Perú. De los Borbones a Bolívar, Lima, Pontificia Universidad Católica del Perú, 2001: 137-172.

Flores Guzmán, Ramiro, «Análisis de la producción minera regional en el Perú borbónico: Pasco, Trujillo y Arequipa (1780-1820)», Margarita Guerra, Cristina Mazzeo y Denisse Rouillon (ed.), Historias Compartidas. Economía, sociedad y poder, siglos XVI-XX, Lima, Pontificia Universidad Católica del Perú, 2007: 345-369.

Gallagher, Mary, «Imperial Reform and the Struggle for Regional Self-Determination: Bishops, Intendants and Creole Elites in Arequipa, Peru (1784-1816)», Tesis de Doctorado, University of New York, 1978.

García Camba, Andrés, Memorias para la Historia de las Armas Españolas en el Perú, Madrid, Tipografía Benito Hortelano, 1846.

Gootenberg, Paul, «Carneros y Chuño: Price Levels in Nineteenth-Century Peru», The Hispanic American Historical Review, 70 / 1 (Duke, 1990): 1-56.

Gootenberg, Paul, Población y etnicidad en el Perú republicano (siglo XIX), Documento de Trabajo n. ${ }^{\circ}$ 71, Lima, Instituto de Estudios Peruanos, 1995. 
Gootenberg, Paul, Caudillos y Comerciantes. La formación económica del estado peruano, 1820-1860, Cuzco, Centro Bartolomé de las Casas, 1997.

Gonzales Paredes, Ramón, Antonio José de Sucre en la dimensión de su destino, Caracas, Editorial CEC, 2006.

Haigh, Samuel, «Bosquejos del Perú (1825-1827)», Alberto Tauro (ed.), Viajeros en el Perú Republicano, Lima, Universidad Nacional Mayor de San Marcos, 1967: 11-43.

Lofstrom, William Lee, La presidencia de Sucre en Bolivia, Caracas, Academia Nacional de la Historia, 1987.

Malamud, Carlos, «La consolidación de una familia de la oligarquía arequipeña: los Goyeneche», Quinto Centenario, 4 (Madrid, 1982): 49-135.

Mazzeo, Cristina (comp.), Los comerciantes limeños a fines del siglo XVIII. Capacidad y cohesión de una elite 1750-1825, Lima, Pontificia Universidad Católica del Perú, 2000.

Mazzeo, Cristina, «El Consulado de Lima y la política comercial española frente a las coyunturas de cambio de fines del periodo colonial (1806-1821)», Bern Hausberger y Antonio Ibarra (ed.), Comercio y poder en América colonial. Los consulados de comerciantes, siglo XVIII-XIX, Madrid, Frankfurt y México DF, Iberoamericana, Vervuert e Instituto Mora, 2003: 199-233.

Mazzeo, Cristina, «Los comerciantes, el Consulado, y los préstamos al gobierno republicano (Lima-Perú, 1820-1840)», Revista Complutense de Historia de América, 32 (Madrid, 2006): 63-84.

Mazzeo, Cristina, «Los nudos de la desunión: conflictos y divergencias en la dirigencia del ejército realista durante la emancipación del Perú, 1810-1824», Revista de Indias, LXIX / 247 (Madrid, 2009): 105-136.

Miller, John, Memorias del General Guillermo Miller, 2 vols., Lima, Editorial Arica, 1975.

Peraltilla, Artemio, El Coronel Manuel Amat y León 1778-1860, Arequipa, Imprenta El Sol, 1969.

Quiroz Paz-Soldán, Eusebio, «Aspectos Económicos de la Independencia de Arequipa», Tesis de Doctorado, Arequipa, Universidad Nacional de San Agustín, 1976.

Sánchez, Susy, «Norte y sur: Las milicias de Arequipa y Trujillo y la construcción de las diferencias regionales en el Perú (1780-1815)», Cristina Mazzeo (ed.), Las relaciones de poder en el Perú. Estado, regiones e identidades locales Siglos XVII-XIX, Lima, Pontificia Universidad Católica del Perú, 2011: 129-170.

Socolow, Susan, Los mercaderes del Buenos Aires virreinal: familia y comercio, Buenos Aires, Ediciones de la Flor, 1991. 
TePaske, John Jay y Herbert S. Klein, The Royal Treasures of the Spanish Empire in America, vol. I, Durham, Duke University Press, 1982.

Travada y Córdova, Ventura, El suelo de Arequipa convertido en cielo, Lima, Editorial Lumen, 1958.

Vargas Ugarte, Rubén, Documentos inéditos sobre la campaña de Independencia del Perú (1810-1824), Lima, Editorial Milla Batres, 1971.

Villa Esteves, Deolinda, «La elite comercial limeña entre el comercio libre y la guerra de la independencia. El caso de Antonio de Elizalde», Cristina Mazzeo (comp.), Los comerciantes limeños a fines del siglo XVIII. Capacidad y cohesión de una elite 1750-1825, Lima, Pontificia Universidad Católica del Perú, 2000: 133-173.

Villanueva Urteaga, Horacio (ed.), Colección Documental de la Independencia del Perú, tomo XXIII, Lima, Comisión Nacional del Sesquicentenario de la Independencia del Perú, 1973.

Wagner de Reyna, Alberto, «Ocho años de La Serna en el Perú (De la "Venganza" a la “Ernestine")», Quinto Centenario, 8 (Madrid 1985): 37-59.

Wibel, John Frederick, «The Evolution of a Regional Community within Empire Spanish and Peruvian Nation. Arequipa 1780-1845», Tesis de Doctorado, Stanford University, 1975.

Witt, Heinrich, Diario 1824-1890. Un testimonio personal sobre el Perú del siglo XIX, tomo I, Lima, Banco Mercantil, 1992.

Fecha de recepción: 8 de marzo de 2010

Fecha de aceptación: 30 de marzo de 2011

\section{War and economics in Arequipa: the activities of the Spaniard Lucas de la Cotera in a time of crisis, 1821-1824}

The present article seeks to examine the economic context of a Peruvian city during the War of Independence and explains the positive and negative consequences of that war. By examining notarial and tax records held in regional archives it also seeks to reconstruct the business and political activities of the Spanish trader Lucas de la Cotera, who for various reasons became during this brief period the main financier and supplier of the last vice-regal government in Peru.

KeY WORDS: Independence; Arequipa; administration; patriots; Royalists; mercantile; public treasury; vice-regal government; loans; contributions; deposit; warrants. 